\title{
Quantum chemical studies on the structures of some heterocyclic azo disperse dyes
}

\author{
Nesrin Tokay, ${ }^{a^{*}}$ Zeynel Seferoğlu, ${ }^{b}$ Cemil Öğretir, ${ }^{c}$ and Nermin Ertan ${ }^{b}$ \\ ${ }^{a}$ Hacettepe University, Faculty of Science, Chemistry Department, 06532 Beytepe-Ankara, \\ Turkey \\ ${ }^{b}$ Gazi University, Faculty of Arts and Sciences Department of Chemistry, 06500 Teknikokullar, \\ Ankara, Turkey \\ ${ }^{c}$ Eskişehir Osmangazi University, Faculty of Arts and Sciences, Chemistry Department, 26040 \\ Eskişehir, Turkey \\ E-mail:ntokay@hacettepe.edu.tr
}

\begin{abstract}
The ground-state geometries, absorption wavelengths, oscillation strengths for a series of some novel hetarylazoindole derivatives were studied with density functional theory (DFT) and timedependent density functional theory (TD-DFT). All calculations were carried out with Gaussian03 software package. A comparison of the computed and the experimental data revealed that the most appropriate functional and basis sets are B3LYP, 6-31G(d), 6-31G(d,p), and 6$311 \mathrm{G}(\mathrm{d}, \mathrm{p})$. An excellent agreement between the experimental and computed data for $\lambda_{\max }$ determinations were observed.
\end{abstract}

Keywords: Heterocyclic azo disperse dye, density functional theory, TD_DFT, UV-vis spectrum, quantum chemical studies

\section{Introduction}

It has been known for many years that azo compounds are the most widely used compounds in various fields such as the dyeing of textile fiber, the coloring of different materials, colored plastic, and polymer, biological-medical studies and advanced applications in organic synthesis. ${ }^{1-7}$ Azo dyes prepared from heterocyclic coupling components have been investigated to produce bright and strong color shades ranging from yellow to greenish blue on synthetic fabrics. These results led to replacement of the commercial products with the conventional azobenzene disperse dyes. ${ }^{8}$ In our previous publications on hetarylazoindoles, we have described the synthesize and structure analysis along with the spectroscopic properties of some hetarylazoindole dyes. ${ }^{9-11}$ 
The prediction of molecular and spectroscopic properties of dye molecules is an important part in the designing process. One of the most widely used methods to calculate ground-state geometries in computational chemistry is the density functional theory (DFT). ${ }^{12}$ It has been known that the absorption spectrum is related to molecular structure and a relationship between the absorption maximum and the structure is much desired. To achieve this, the experimental spectrum can be compared with the calculated one. The extension of DFT to excited states is known as the time-dependent density-functional theory (TD-DFT) method and has been used to describe optical and spectroscopic properties of the medium size and large molecules. ${ }^{13-15}$

In the present work we have attempted to determine and evaluate the optimized structural parameters, the maximum absorption peaks $\left(\lambda_{\max }\right)$ in the ultraviolet and visible (UV-vis) spectra of the studied hetarylazoindole dyes using DFT and TD-DFT methods, and possible correlations were searched between experimental and computational data.

\section{Computational methodology}

In order to determine the most appropriate quantum chemical approach for hetarylazoindole dyes, quantum-chemical calculations of compound $\mathbf{2}$ have been performed using Becke's three parameter exchange function (B3) with Lee-Yang-Parr correlation function (LYP), and Perdew, Burke, and Ernzerhof (PBE) ${ }^{16}$ functionals with several basis-sets: 6-31G, 6-31G(d), 6-31G(d,p), 6-311G(d,p), 6-311G(2d,2p), 6-31+G(d,p), and 6-311++G(d,p) respectively. ${ }^{17-18}$ Geometry optimizations of hetarylazoindole dyes and their model compounds in gas phase were carried out at DFT level of theory using B3LYP with three basis sets without any symmetry restrictions. All optimized geometries have been confirmed by frequency analyses at the same level of theory.

Calculations of $\lambda_{\max }$ in the UV-vis spectrum corresponding to the vertical excitation energies were carried out by using TD-DFT method with the B3LYP functional and the same 6-31G(d), 6-31G(d,p), and 6-311G(d,p) basis sets selected for geometry optimization. For the TD-DFT calculations the Polarizable Continuum Model (PCM) was used to take care of the solvent effects. $^{19-20}$

The Gaussian 03 package of programs ${ }^{21}$ has been chosen to perform geometry optimizations, frequency calculations and to determine the maximum absorption peaks.

\section{Results and Discussion}

The formulae of studied compounds are depicted in Figure 1. Initially the optimized geometrical data of compound 2 has been determined by using B3LYP and PBE1 functions with several basis sets. Compound $\mathbf{2}$ has been chosen for this step because the structure of the dye has been analyzed by x-ray diffraction method. ${ }^{11}$ The optimized geometrical parameters and X-ray crystallographic data were collected in Table 1. 


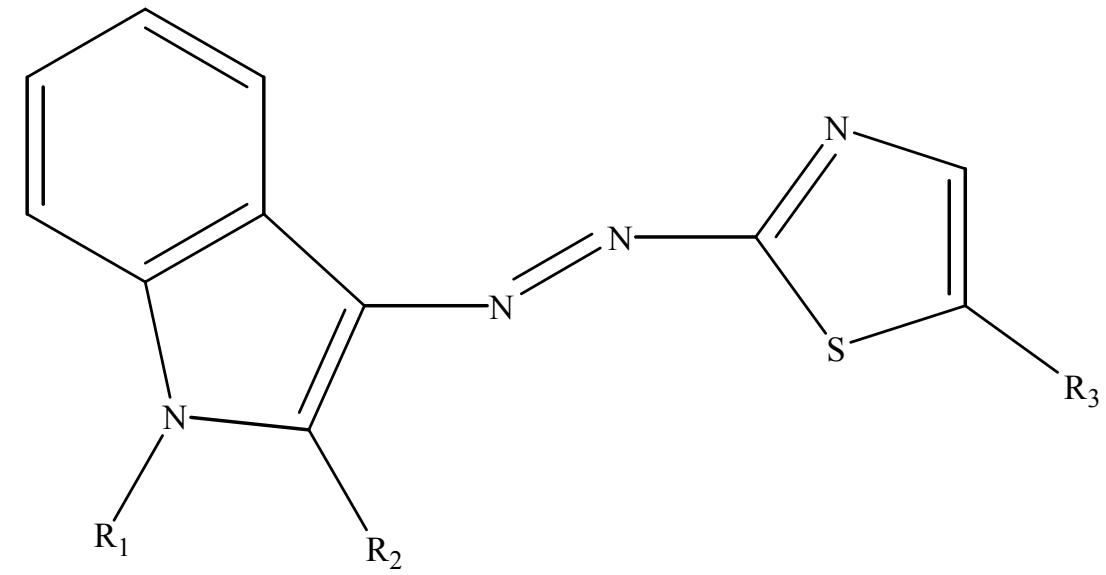

II
1. $\mathrm{R}_{1}=\mathrm{H}, \mathrm{R}_{2}=\mathrm{Ph}, \mathrm{R}_{3}=\mathrm{H}$
7. $\mathrm{R}_{1}=\mathrm{H}, \mathrm{R}_{2}=\mathrm{CH}_{3}, \mathrm{R}_{3}=\mathrm{H}$
2. $\mathrm{R}_{1}=\mathrm{H}, \mathrm{R}_{2}=\mathrm{Ph}, \mathrm{R}_{3}=\mathrm{CH}_{3}$
8. $\mathrm{R}_{1}=\mathrm{H}, \mathrm{R}_{2}=\mathrm{R}_{3}=\mathrm{CH}_{3}$
3. $\mathrm{R}_{1}=\mathrm{H}, \mathrm{R}_{2}=\mathrm{Ph}, \mathrm{R}_{3}=\mathrm{NO}_{2}$
9. $\mathrm{R}_{1}=\mathrm{H}, \mathrm{R}_{2}=\mathrm{CH}_{3}, \mathrm{R}_{3}=\mathrm{NO}_{2}$
4. $\mathrm{R}_{1}=\mathrm{CH}_{3}, \mathrm{R}_{2}=\mathrm{Ph}, \mathrm{R}_{3}=\mathrm{H}$
10. $\mathrm{R}_{1}=\mathrm{CH}_{3}, \mathrm{R}_{2}=\mathrm{CH}_{3}, \mathrm{R}_{3}=\mathrm{H}$
5. $\mathrm{R}_{1}=\mathrm{CH}_{3}, \mathrm{R}_{2}=\mathrm{Ph}, \mathrm{R}_{3}=\mathrm{CH}_{3}$
11. $\mathrm{R}_{1}=\mathrm{CH}_{3}, \mathrm{R}_{2}=\mathrm{R}_{3}=\mathrm{CH}_{3}$
6. $\mathrm{R}_{1}=\mathrm{CH}_{3}, \mathrm{R}_{2}=\mathrm{Ph}, \mathrm{R}_{3}=\mathrm{NO}_{2}$
12. $\mathrm{R}_{1}=\mathrm{CH}_{3}, \mathrm{R}_{2}=\mathrm{CH}_{3}, \mathrm{R}_{3}=\mathrm{NO}_{2}$

Figure 1. The formulae of studied hetarylazoindole derivatives.

As can be seen from the Table 1, the differences between optimized geometrical parameters and X-ray crystallographic data for $\mathrm{C}_{18}-\mathrm{S}_{19}$ bond length are greatest (max. diff.: 0.143 , min. diff.: 0.028), but for $\mathrm{C}_{2}-\mathrm{C}_{10}$ are less (max. diff.: $0.002 \mathrm{~min}$. diff.: -0.004 ) for both functionals and all basis sets. The comparison of optimized and x-ray crystallographic data of bond angles (Table 2) gives the highest differences for $\mathrm{N}_{16}-\mathrm{N}_{17}-\mathrm{C}_{18}$ (max. diff.: 4.74, min. diff.: 2.27) and less differences for $\mathrm{C}_{4}-\mathrm{C}_{3}-\mathrm{C}_{9}$ (max. diff.: 0.11, min. diff.:- 0.33) bond angles. As shown in Section 3, the combinations B3LYP functional with 6-31G(d), 6-31G(d,p), and 6-311G(d,p) basis sets provide the best agreement between calculated values and x-ray crystallographic data. The DFT results have indicated that the agreement between calculated and experimental data was acceptable. 
Table 1. Comparison of some calculated and experimental bond lengths $(\AA)$ of compound 2
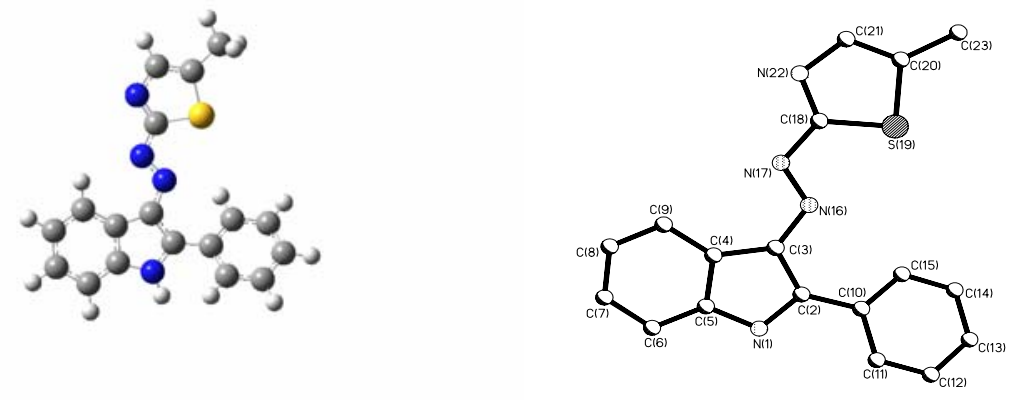

B3LYP/6-311G(d,p)

X-ray

\begin{tabular}{lccccccccc}
\hline Functional/ Basis set & $\mathrm{N}_{1}-\mathrm{C}_{2}$ & $\mathrm{C}_{3}-\mathrm{N}_{16}$ & $\mathrm{C}_{2}-\mathrm{C}_{10}$ & $\mathrm{~N}_{16}-\mathrm{N}_{17}$ & $\mathrm{~N}_{17}-\mathrm{C}_{18}$ & $\mathrm{C}_{18}-\mathrm{S}_{19}$ & $\mathrm{C}_{18}-\mathrm{N}_{22}$ & $\mathrm{~S}_{19}-\mathrm{C}_{20}$ & $\mathrm{~N}_{22}-\mathrm{C}_{21}$ \\
\hline B3LYP/ & & & & & & & & & \\
6-31G & 1.381 & 1.370 & 1.462 & 1.256 & 1.375 & 1.873 & 1.308 & 1.813 & 1.383 \\
6-31G(d) & 1.373 & 1.369 & 1.463 & 1.278 & 1.380 & 1.788 & 1.307 & 1.747 & 1.367 \\
6-31G(d.p) & 1.373 & 1.369 & 1.463 & 1.278 & 1.380 & 1.788 & 1.306 & 1.747 & 1.368 \\
6-311G(d.p) & 1.371 & 1.368 & 1.463 & 1.271 & 1.379 & 1.786 & 1.302 & 1.745 & 1.365 \\
6-311G(2d.2p) & 1.369 & 1.368 & 1.461 & 1.270 & 1.379 & 1.779 & 1.301 & 1.741 & 1.364 \\
6-311G++(d.p) & 1.371 & 1.368 & 1.463 & 1.271 & 1.380 & 1.784 & 1.303 & 1.745 & 1.366 \\
PBE1/ & & & & & & & & & \\
6-31G & 1.374 & 1.365 & 1.457 & 1.288 & 1.373 & 1.844 & 1.305 & 1.797 & 1.378 \\
6-31G(d) & 1.365 & 1.365 & 1.459 & 1.269 & 1.377 & 1.767 & 1.303 & 1.732 & 1.361 \\
6-31G(d.p) & 1.365 & 1.365 & 1.459 & 1.269 & 1.377 & 1.766 & 1.303 & 1.732 & 1.361 \\
6-311G(d.p) & 1.364 & 1.364 & 1.458 & 1.263 & 1.376 & 1.764 & 1.299 & 1.731 & 1.359 \\
6-311G(2d.2p) & 1.362 & 1.364 & 1.460 & 1.262 & 1.376 & 1.758 & 1.298 & 1.727 & 1.358 \\
6-311G++(d.p) & 1.363 & 1.364 & 1.458 & 1.263 & 1.377 & 1.763 & 1.299 & 1.731 & 1.360 \\
X-ray & 1.355 & 1.372 & 1.461 & 1.281 & 1.389 & 1.730 & 1.302 & 1.725 & 1.372 \\
\hline
\end{tabular}


Table 2. Comparison of some calculated and experimental bond angles $\left({ }^{\circ}\right)$ of compound 2

\begin{tabular}{lccccccc}
\hline $\begin{array}{l}\text { Functional/ } \\
\text { Basis set }\end{array}$ & $\mathrm{C}_{5}-\mathrm{N}_{1}-\mathrm{C}_{2}$ & $\mathrm{~N}_{1}-\mathrm{C}_{2}-\mathrm{C}_{10}$ & $\mathrm{C}_{3}-\mathrm{N}_{16}-\mathrm{N}_{17}$ & $\mathrm{~N}_{16}-\mathrm{N}_{17}-\mathrm{C}_{18}$ & $\mathrm{~N}_{17}-\mathrm{C}_{18}-\mathrm{S}_{19}$ & $\mathrm{~N}_{17}-\mathrm{C}_{18}-\mathrm{N}_{22}$ & $\mathrm{C}_{18}-\mathrm{N}_{22}-\mathrm{C}_{21}$ \\
\hline B3LYP/ & & & & & & & \\
6-31G & 110.97 & 121.13 & 116.39 & 115.52 & 122.85 & 123.92 & 112.77 \\
6-31G(d) & 110.82 & 120.83 & 115.43 & 113.61 & 123.35 & 122.27 & 110.74 \\
6-31G(d.p) & 110.79 & 120.84 & 115.42 & 113.61 & 123.35 & 122.27 & 110.75 \\
6-311G(d.p) & 110.75 & 120.80 & 115.57 & 114.03 & 123.33 & 122.40 & 111.01 \\
6-311G(2d.2p) & 110.69 & 120.77 & 115.57 & 114.10 & 123.53 & 122.27 & 110.96 \\
6-311G++(d.p) & 110.72 & 120.86 & 115.77 & 114.06 & 123.40 & 122.42 & 111.07 \\
PBE1/ & & & & & & & 123 \\
6-31G & 110.98 & 121.21 & 116.43 & 115.03 & 122.62 & 123.70 & 112.33 \\
6-31G(d) & 110.84 & 120.90 & 115.35 & 113.05 & 123.03 & 122.24 & 110.38 \\
6-31G(d.p) & 110.80 & 120.91 & 115.33 & 113.05 & 123.02 & 122.25 & 110.40 \\
6-311G(d.p) & 110.74 & 120.86 & 115.43 & 113.40 & 122.98 & 122.34 & 110.57 \\
6-311G(2d.2p) & 110.68 & 120.80 & 115.37 & 113.42 & 123.14 & 122.26 & 110.51 \\
6-311G++(d.p) & 110.70 & 120.93 & 115.62 & 113.40 & 123.00 & 122.42 & 110.64 \\
X-ray & 110.41 & 120.69 & 115.34 & 110.78 & 124.12 & 121.10 & 109.80 \\
\hline
\end{tabular}

The UV-vis data of compound 2 was calculated with TD-DFT using the same functions and basis sets which were used in geometry optimization. Table 3 lists the data of calculated $\lambda_{\max }$ for compound 2. From Tables 1-3, it was concluded that the combinations of B3LYP functional with 6-31G(d), 6-31G(d,p), and 6-311G(d,p) basis sets provide the best results in $\mathrm{CHCl}_{3}$.

Table 3. Functional and basis set studies for compound $\mathbf{2}$

\begin{tabular}{lcccc}
\hline \multirow{2}{*}{ Basis set } & \multicolumn{2}{c}{ B3LYP } & \multicolumn{2}{c}{ PBE1 } \\
\cline { 2 - 5 } 6-31G & $\lambda_{\max }(\mathrm{nm})$ & $\mathrm{f}$ & $\lambda_{\max }(\mathrm{nm})$ & $\mathrm{f}$ \\
6-31G(d) & 465.53 & 0.685 & 446.98 & 0.710 \\
6-31G(d,p) & 452.91 & 0.670 & 436.09 & 0.701 \\
6-311G(d,p) & 453.05 & 0.669 & 436.45 & 0.700 \\
$6-311 \mathrm{G}(2 \mathrm{~d}, 2 \mathrm{p})$ & 451.99 & 0.671 & 436.05 & 0.699 \\
6-311G++(d,p) & 455.03 & 0.514 & 439.40 & 0.672 \\
\hline
\end{tabular}

*The experimental value is $452 \mathrm{~nm}$. 
In order to obtain the stable geometries, three different basis sets, 6-31G(d), 6-31G(d,p), and 6-311G(d,p) with B3LYP functional were used for the calculations of hetarylazoindole dyes. It was understood from the results that the molecular framework of the dyes is planar. The substituents on $\mathrm{C}-2$ or $\mathrm{C}-20$ do not distort the skeleton. For Group I molecules the phenyl group was found out of plane of the molecule. The dihedral angle $C_{11}-C_{10}-C_{2}-N_{1}$ is nearly $-30^{\circ}$ for Group I molecules and $-47^{\circ}$ for their model compounds (for example, the x-ray data for compound 2 is $-19.685^{\circ}$ ).

The calculated and experimental $\lambda_{\max }$ and the oscillator strengths for the studied hetarylazoindole molecules are listed in Table 4. The PCM-TD-B3LYP approach was applied to the dyes to determine the effect of solvent on $\lambda_{\max }$. The method represents the excitation corresponding HOMO-LUMO transition with the strongest oscillator strength. The absolute deviation range between calculated and experimental $\lambda_{\max }$ is from 0 to $29 \mathrm{~nm}$ and from 7 to 35 $\mathrm{nm}$ for chloroform and methanol solution respectively.

In order to consider the effect of solvent on absorption spectra, calculated absorption wavelengths based on TD-B3LYP/6-31G(d,p) level are plotted against the experimental values with the fitted lines (Figure 2). It could be seen that the results are quite satisfactory for both solvent.As can be seen from the data given in Table 4 , the sequence of calculated $\lambda_{\max }$ is $\mathrm{NO}_{2}>$ $\mathrm{CH}_{3}>\mathrm{H}$ for substituents attached to $\mathrm{C}-20$ position for each group of the hetarylazoindole dyes. This sequence is consistent with the experimental results. The electronic transition from HOMO to LUMO corresponds to the low energy absorption. Table 5 lists the energies of the frontier orbitals of the studied molecules. The sequence of excitation energy for the substituents attached to $\mathrm{C}-20$ position is $\mathrm{H}>\mathrm{CH}_{3}>\mathrm{NO}_{2}$. Because of the increasing effect on $\pi$-electron density of the electron-donor substituent on C-20, the energy from HOMO to LUMO becomes lower (such as compound 3). The conjugated system becomes larger when the phenyl group is attached to $\mathrm{C}-2$ position (Group I molecules). This makes the energy band gap of the conjugated system lower, and $\lambda_{\max }$ longer.

Figure 3 provides a graphical representation of the frontier orbitals. It can be seen from Figure 3 that the electron density of HOMO of compound $\mathbf{2}$ is localized on azoindole moiety, and the electron density of LUMO is distributed at the main molecular skeleton. The frontier molecular orbitals of the other dye molecules are similar to that of compound 2 . The results of TD-DFT calculations demonstrate that the color of the studied dye compounds mainly corresponds to an electron excitation from HOMO to LUMO. 
Table 4. Computed and experimental $\lambda_{\max }(\mathrm{nm})$ with parenthesized oscillator strength (f) for the hetarylazoindole derivatives.

\begin{tabular}{|c|c|c|c|c|c|c|c|c|c|c|c|c|}
\hline \multirow[b]{2}{*}{ Basis set } & \multicolumn{12}{|c|}{ Compound } \\
\hline & 1 & 2 & 3 & 4 & 5 & 6 & 7 & 8 & 9 & 10 & 11 & 12 \\
\hline & \multicolumn{12}{|c|}{ Solvent : Chloroform } \\
\hline $6-31 G(d)$ & $\begin{array}{l}446.48 \\
(0.620)\end{array}$ & $\begin{array}{l}452.91 \\
(0.670)\end{array}$ & $\begin{array}{l}514.69 \\
(0.618)\end{array}$ & $\begin{array}{l}436.18 \\
(0.687)\end{array}$ & $\begin{array}{l}442.62 \\
(0.747)\end{array}$ & $\begin{array}{l}505.38 \\
(0.413)\end{array}$ & $\begin{array}{l}413.18 \\
(0.767)\end{array}$ & $\begin{array}{l}419.16 \\
(0.838)\end{array}$ & $\begin{array}{l}482.05 \\
(0.812)\end{array}$ & $\begin{array}{l}416.91 \\
(0.819)\end{array}$ & $\begin{array}{l}422.99 \\
(0.889)\end{array}$ & $\begin{array}{l}485.21 \\
(0.874)\end{array}$ \\
\hline 6-31G(d,p) & $\begin{array}{l}446.70 \\
(0.619)\end{array}$ & $\begin{array}{l}453.05 \\
(0.669)\end{array}$ & $\begin{array}{l}514.83 \\
(0.616)\end{array}$ & $\begin{array}{l}436.24 \\
(0.687)\end{array}$ & $\begin{array}{l}442.72 \\
(0.748)\end{array}$ & $\begin{array}{l}505.36 \\
(0.404)\end{array}$ & $\begin{array}{l}413.04 \\
(0.768)\end{array}$ & $\begin{array}{l}419.06 \\
(0.838)\end{array}$ & $\begin{array}{l}482.06 \\
(0.810)\end{array}$ & $\begin{array}{l}416.84 \\
(0.821)\end{array}$ & $\begin{array}{l}422.96 \\
(0.890)\end{array}$ & $\begin{array}{l}485.20 \\
(0.874)\end{array}$ \\
\hline $6-311 G(d, p)$ & $\begin{array}{l}445.11 \\
(0.622)\end{array}$ & $\begin{array}{l}451.99 \\
(0.671)\end{array}$ & $\begin{array}{l}519.80 \\
(0.627)\end{array}$ & $\begin{array}{l}434.66 \\
(0.697)\end{array}$ & $\begin{array}{l}441.55 \\
(0.756)\end{array}$ & $\begin{array}{l}499.93 \\
(0.399)\end{array}$ & $\begin{array}{l}413.60 \\
(0.772)\end{array}$ & $\begin{array}{l}419.82 \\
(0.840)\end{array}$ & $\begin{array}{l}481.36 \\
(0.807)\end{array}$ & $\begin{array}{l}417.69 \\
(0.825)\end{array}$ & $\begin{array}{c}423.98 \\
(0.892)\end{array}$ & $\begin{array}{l}485.16 \\
(0.871)\end{array}$ \\
\hline \multirow[t]{2}{*}{ Experimental } & 437 & 452 & 526 & 431 & 451 & 524 & 415 & 416 & 504 & 438 & 442 & 514 \\
\hline & \multicolumn{12}{|c|}{ Solvent: Methanol } \\
\hline $6-31 G(d)$ & $\begin{array}{l}444.91 \\
(0.589)\end{array}$ & $\begin{array}{l}451.41 \\
(0.599)\end{array}$ & $\begin{array}{l}518.88 \\
(0.555)\end{array}$ & $\begin{array}{l}434.95 \\
(0.662)\end{array}$ & $\begin{array}{l}441.70 \\
(0.723)\end{array}$ & $\begin{array}{l}507.81 \\
(0.561)\end{array}$ & $\begin{array}{l}412.20 \\
(0.745)\end{array}$ & $\begin{array}{l}418.50 \\
(0.817)\end{array}$ & $\begin{array}{l}485.13 \\
(0.778)\end{array}$ & $\begin{array}{l}415.72 \\
(0.795)\end{array}$ & $\begin{array}{l}422.15 \\
(0.866)\end{array}$ & $\begin{array}{l}487.32 \\
(0.838)\end{array}$ \\
\hline 6-31G(d,p) & $\begin{array}{l}445.13 \\
(0.588)\end{array}$ & $\begin{array}{c}451.61 \\
(0.597)\end{array}$ & $\begin{array}{l}519.07 \\
(0.553)\end{array}$ & $\begin{array}{l}435.00 \\
(0.662)\end{array}$ & $\begin{array}{l}441.79 \\
(0.724)\end{array}$ & $\begin{array}{c}507.79 \\
(0.5595)\end{array}$ & $\begin{array}{l}412.07 \\
(0.745)\end{array}$ & $\begin{array}{l}418.41 \\
(0.818)\end{array}$ & $\begin{array}{l}485.17 \\
(0.776)\end{array}$ & $\begin{array}{l}415.65 \\
(0.797)\end{array}$ & $\begin{array}{l}422.13 \\
(0.868)\end{array}$ & $\begin{array}{l}487.34 \\
(0.838)\end{array}$ \\
\hline $6-311 G(d, p)$ & $\begin{array}{l}443.40 \\
(0.594)\end{array}$ & $\begin{array}{l}450.45 \\
(0.619)\end{array}$ & $\begin{array}{l}523.39 \\
(0.570)\end{array}$ & $\begin{array}{l}433.41 \\
(0.672)\end{array}$ & $\begin{array}{l}440.61 \\
(0.733)\end{array}$ & $\begin{array}{l}504.96 \\
(0.587)\end{array}$ & $\begin{array}{l}412.47 \\
(0.750)\end{array}$ & $\begin{array}{l}419.04 \\
(0.820)\end{array}$ & $\begin{array}{l}484.10 \\
(0.774)\end{array}$ & $\begin{array}{l}416.33 \\
(0.801)\end{array}$ & $\begin{array}{l}423.01 \\
(0.870)\end{array}$ & $\begin{array}{l}486.97 \\
(0.835)\end{array}$ \\
\hline Experimental & 459 & 464 & 539 & 444 & 453 & 522 & 419 & 444 & 509 & 444 & 443 & 522 \\
\hline
\end{tabular}


Table 5. Frontier orbital energies (eV) for hetarylazoindole derivatives at TD-B3LYP/6-31G(d,p) level

\begin{tabular}{|c|c|c|c|c|c|c|c|c|c|c|c|c|}
\hline \multirow[b]{3}{*}{$\begin{array}{l}\text { Frontier } \\
\text { orbital }\end{array}$} & \multicolumn{12}{|c|}{ Compound } \\
\hline & 1 & 2 & 3 & 4 & 5 & 6 & 7 & 8 & 9 & 10 & 11 & 12 \\
\hline & \multicolumn{12}{|c|}{ Solvent : Chloroform } \\
\hline HOMO & -5.47 & -5.40 & -5.86 & -5.44 & -5.37 & -5.85 & -5.51 & -5.44 & -5.94 & -5.47 & -5.39 & -6.08 \\
\hline LUMO & -2.41 & -2.38 & -3.17 & -2.33 & -2.29 & -3.12 & -2.25 & -2.22 & -3.12 & -2.24 & -2.21 & -3.28 \\
\hline \multirow[t]{2}{*}{$E^{a}$} & 3.06 & 3.02 & 2.69 & 3.12 & 3.08 & 2.73 & 3.26 & 3.22 & 2.82 & 3.23 & 3.19 & 2.81 \\
\hline & \multicolumn{12}{|c|}{ Solvent: methanol } \\
\hline HOMO & -5.52 & -5.46 & -5.85 & -5.52 & -5.45 & -5.84 & -5.57 & -5.50 & -5.92 & -5.75 & -5.47 & -6.09 \\
\hline LUMO & -2.48 & -2.46 & -3.20 & -2.42 & -2.40 & -3.17 & -2.33 & -2.31 & -3.16 & -2.53 & -2.31 & -3.32 \\
\hline $\mathrm{E}^{\mathrm{a}}$ & 3.04 & 3.00 & 2.65 & 3.10 & 3.06 & 2.66 & 3.23 & 3.19 & 2.77 & 3.22 & 3.16 & 2.77 \\
\hline
\end{tabular}

${ }^{\mathrm{a}} \mathrm{E}=\mathrm{LUMO}-\mathrm{HOMO}$; the energy gap. 


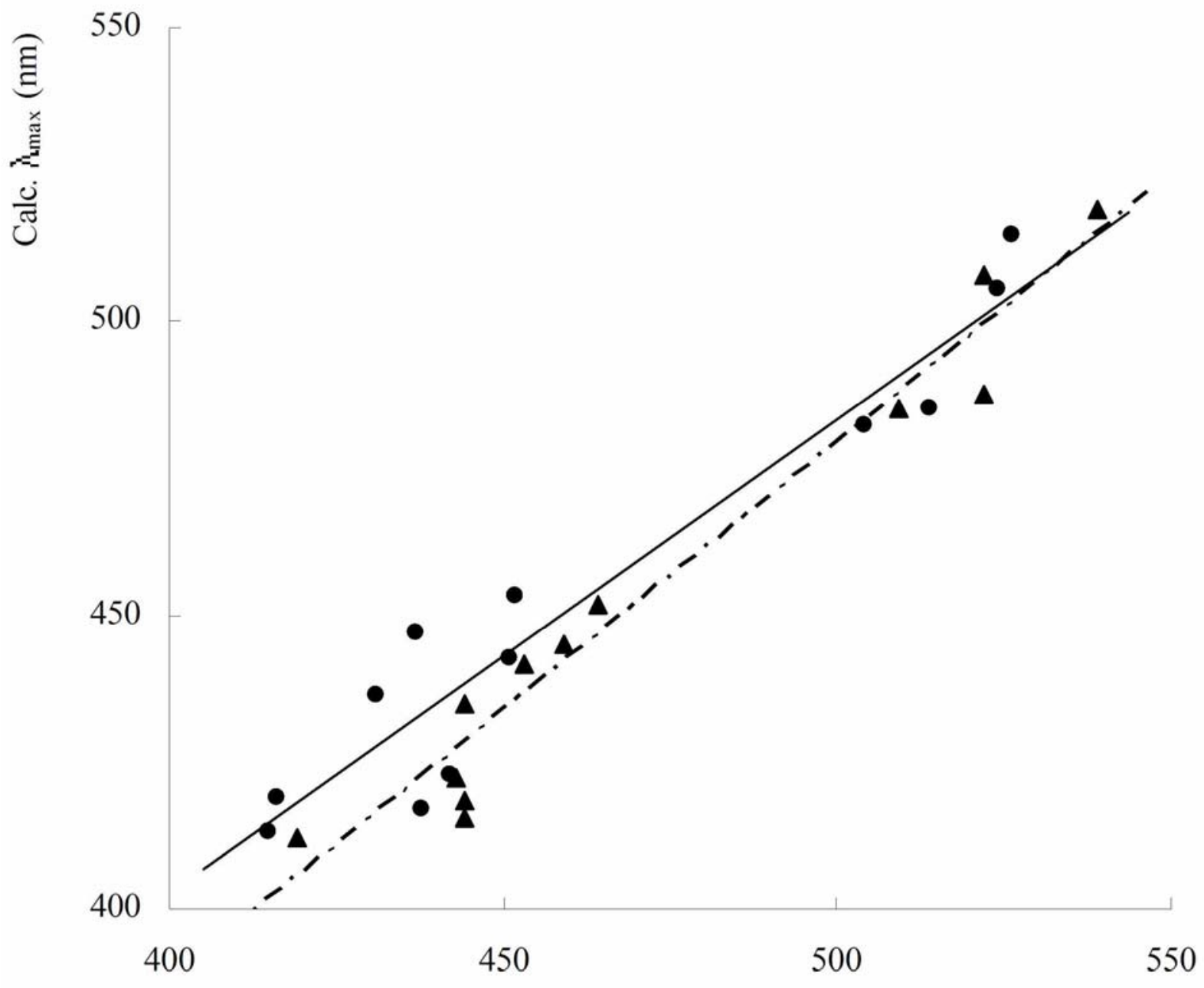

Exp. $\lambda_{\max }(\mathrm{nm})$

Figure 2. The correlation between the experimental and calculated values (at TDB3LYP/631G(d,p)level) of $\lambda_{\max }$ of the UV-vis spectra for the studied hetarylazoindole derivative solutions at (a) chloroform $\left(\boldsymbol{\Lambda}, \mathrm{r}^{2}=0.9244\right)$ (b) methanol $\left(\bullet, \mathrm{r}^{2}=0.9559\right)$. 


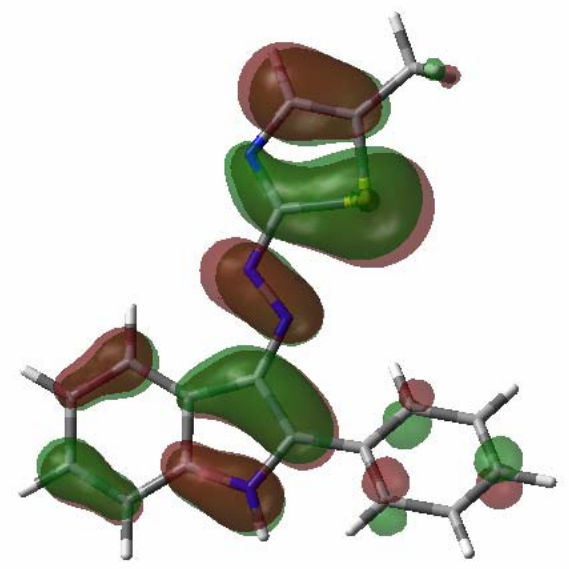

(a)

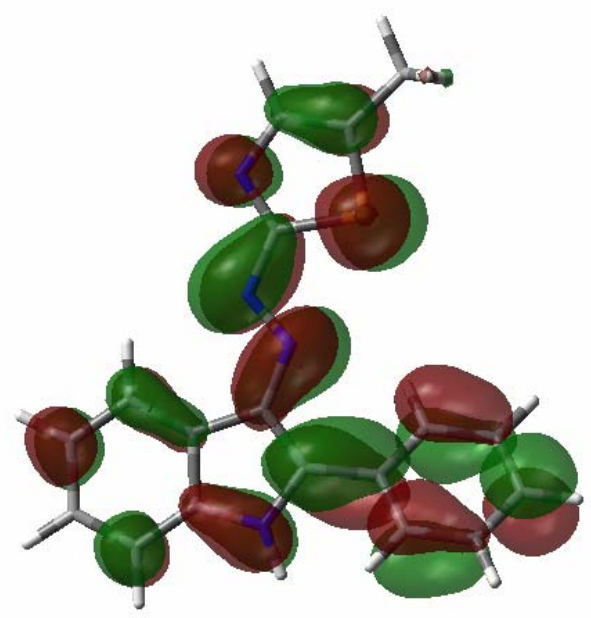

(b)

Figure 3. The frontier orbitals : (a) HOMO and (b) LUMO for 2 (at TD-B3LYP/6-311G(d,p)level). 


\section{Conclusions}

The optimized geometries of the studied compounds were calculated by B3LYP/6-31G(d), B3LYP/6-31G(d,p), and B3LYP/6-311G(d,p) levels of theory and it was found to be in good agreement with the experimental data. The TD-DFT has been used to determine the UV-vis spectra of all compounds. The agreement between the calculated and experimental maximum absorption wavelengths is excellent. In addition, it can be suggested that TD-DFT method is a valuable method in the prediction of the excitation states for this type of compounds.

Another important conclusion that we can draw from these calculations is that the results of the frontier orbital calculations are indicating that the nucleophilicity (i.e. $\mathrm{E}_{\text {HOMO-}}-\mathrm{E}_{\text {LUMO }}$ ) of molecule 3 is the highest among the studied molecules (Table 5). Since nucleophilicity is closely related to basicity the knowledge of predicted nucleophilicity can be very important in fixation and similar process. This means calculation and prediction methods can safely be applied.

\section{Acknowledgements}

This work was supported by the Scientific and Technological Research Council of Turkey (TBAG-HD 101T224).

\section{References}

1. Hunger, K. Industrial Dyes, Chemistry, Properties, Applications, Wiley-VCH: Weinheim, 2003; pp 20-35.

2. Catino, S. C.; Farris, R. E. Azo Dyes, Grayson, M., Ed.; Concise Encyclopedia of Chemical Technology, John Wiley and Sons: New York, 1985; pp 142-144.

3. Zollinger, H. Color Chemistry, Synthesis, Properties and Aplications of Organic Dyes and Pigments, Third revised edition, Wiley-VCH Verlag: Weinheim, 2003.

4. Bahatti, H. S.; Seshadri, S. Coloration Technology 2004, 120, 151.

5. Tanaka, K.; Matsuo, K.; Nakanishi, A.; Shiota, J.H. Yamaguchi, M.; Yoshino, S. Chem. Pharm. Bull. 1984, 32, 391.

6. Fadda, A. A.; Etmen, H. A.; Amer, F. A.; Barghout, M.; Mohammed, K. S. J. Chem. Technol. Biotechnology 1994, 61, 343.

7. Ertan, N.; Eyduran, F. Dyes and Pigments 1995, 27, 313.

8. Towns, A. D. Dyes and Pigments 1999, 42, 3.

9. Seferoğlu, Z.; Ertan, N. Heteroatom Chemistry 2007, 18, 662.

10. Seferoğlu, Z.; Hökelek, T.; Şahin, E.; Ertan, N. Acta Cryst. E. 2006, 62, 3835.

11. Seferoğlu, Z. Ph.D. Thesis, Institue of Science and Technology, Gazi University, 2006.

12. Parr, R. R.; Yang, R. G. Density functional theory of atoms and molecules, Oxford 
University Press: New York, 1989.

13. Jamorski, C. ; Casida, M. E. ; Salahub, D. R. J. Phys. Chem. 1996, 104, 5134.

14. Bauerschmitt, R.; Alrichs, R. Chem. Phys. Lett. 1996, 256, 454.

15. Bauerschmitt, R.; Häser, M.; Treutler, O.; Alrichs, R. Chem. Phys. Lett., 1997, 264, 573.

16. Perdew, J. P.; Burke, K.; Ernzerhof, M. Phys. Rev. Lett. 1996, 77, 3865.

17. Becke, A. D. J. Phys. Chem. 1993, 98, 5648.

18. Lee, C.; Yang, W.; Parr, R. G. Phys. Rev. 1988, B37, 785.

19. Cossi, M.; Barone, V. J. Chem. Phys. 2001, 115, 4708.

20. Miertus, S.; Scrocco, E.; Tomasi, J. Chem. Phys. 1981, 55, 117.

21. Frisch, M. J. et al., Gaussian. Inc., Wallingford, CT, 2004. 